\title{
New guidelines for metabolic targets in diabetes: clinician's opinion does matter
}

\author{
Katherine Esposito • Maria Ida Maiorino • \\ Giuseppe Bellastella $\cdot$ Dario Giugliano
}

Received: 23 January 2014/Accepted: 4 February 2014/Published online: 18 February 2014

(C) Springer Science+Business Media New York 2014

\begin{abstract}
Evidence-based medicine replaced eminencebased medicine as a way to manage unavoidable clinical uncertainty. Moving away from "one-size-fits-all" medicine, personalized medicine seemed to have the potential of tailoring therapies to subsets of patients. Despite the rapid progress in drug development for diabetes, it is still challenging to achieve good glycemic control in a substantial population. Different diabetes management algorithms have been proposed: most agree with a HbAlc target of $<7.0 \%$ for the majority of people with diabetes, except the American Association of Clinical Endocrinologists (AACE) that claims for a lower HbA1c target $(<6.5 \%)$. The recently released American guidelines on the treatment of blood cholesterol recommends moderate-intensity statin therapy for primary prevention for persons aged 40-75 years with type 1 or 2 diabetes and LDL-cholesterol levels between 70 and $189 \mathrm{mg} / \mathrm{dl}$. The Eighth Joint National Committee recommends pharmacologic treatment in the population aged 18 years or older with diabetes, with a goal systolic blood pressure of lower than $140 \mathrm{mmHg}$ and a goal diastolic blood pressure lower than $90 \mathrm{mmHg}$. There are differences and similarities among these recent guidelines for people with diabetes, with the main differences related to the level of the evidence. There are recommendations based on expert opinions (insufficient evidence or existing evidence unclear or conflicting) in almost all
\end{abstract}

\footnotetext{
K. Esposito

Department of Clinical and Experimental Medicine, Second

University of Naples, Naples, Italy
}

M. I. Maiorino · G. Bellastella · D. Giugliano ( $\square)$

Department of Medical, Surgical, Neurological, Metabolic

Sciences, and Geriatrics, Second University of Naples, Naples, Italy

e-mail: dario.giugliano@unina2.it guidelines. The ultimate decision about care of a particular patient is left to clinicians, as the way to manage unavoidable guideline uncertainty: clinician's opinion does matter.

Keywords Guidelines - Diabetes mellitus - Metabolic targets

\section{Introduction}

Each patient should receive the most appropriate care. This statement hardly can find an opponent. Eminence-based medicine has long relied on clinical experience and expert opinion for clinical decision-making. The seminal studies of the Nobel laureates Tversky and kahneman [1] of how people manage risk and uncertainty disclosed that people rely on a limited number of heuristic principles, which reduce the complex tasks of assessing probabilities to simpler judgment operations. While this attitude of the human mind is quite useful, sometimes it leads to errors.

Eminence-based medicine was therefore replaced by evidence-based medicine, which identifies important knowledge gaps and information needs, formulates answerable questions, and assesses the validity of evidence and results. As originally defined by Sackett and Rosemberg [2], evidence-based medicine indicated the ability to track down, critically appraise, and incorporate the rapidly growing body of evidence into one's clinical practice. On the other hand, evidence-based medicine must rely on inductive reasoning to draw conclusions about the effectiveness and feasibility of application of trial data (mean group data) to individual patients. As a corollary, doctors have to do everything possible to reduce the chance of error. 
At the turn of this century, scientists began to realize the promise of the Human Genome Project, as a way to identify predisposition to disease and to tailor treatment to the individual [3]. Later, the term "personalized medicine" had the capacity to attract media attention, as genomic medicine seemed to be leading toward a reductionist view of life, where health and disease is determined primarily by genetic difference. Moving away from "one-size-fits-all" medicine, personalized medicine had the potential of tailoring therapies to subsets of patients based on their likelihood to respond to therapy or their risk of adverse events. The challenge is how to identify these patients, and deliver truly personalized care that maximizes benefit and minimizes harm [4]. In the real world of individual patients, eminence-based, evidence-based, and personalized medicine cannot abandon clinical judgment [5].

Diabetes: still far from the metabolic targets

Despite the rapid progress in drug development for diabetes, it is still challenging to achieve good glycemic control in a substantial population. The data from the National Health and Nutrition Examination Survey and the Behavioral Risk Factor Surveillance System over the 1999-2010 period show that $52 \%$ of survey participants (adults with self-reported diabetes) achieved the hemoglobin A1c (HbA1c) target $<7 \%$ from 2007 through 2010 [6]. For blood pressure, 52\% of participants reached the $<130 / 80 \mathrm{mmHg}$ target, and $72 \%$ fell below the less ambitious target of $<140 / 90 \mathrm{mmHg}$. Finally, $56 \%$ of participants reached the $<100 \mathrm{mg} / \mathrm{dl}$ LDL-cholesterol target. Interestingly enough, the percentages of people with diabetes achieving the blood pressure and LDL-cholesterol targets increased steadily from 1999 to 2010, while those achieving the HbA1c target showed a slight decrease from the $56 \%$ of the previous period 2003-2006. Quite surprisingly, type 1 diabetic people, who in theory would benefit more from lower HbA1c targets, present the worst performance, with percentages of $24 \%$ for $\mathrm{HbA} 1 \mathrm{c}<7 \%$, and $12.3 \%$ for $\mathrm{HbA} 1 \mathrm{c}<6.5 \%$ (percentages based on 24,428 patients with type 1 diabetes in Italy in 2009) [7].

New guideline for metabolic health in people with diabetes

The prevalence of clinical guidelines is very unlikely to decrease, also considering that about half of the major recommendations in guidelines become outdated in approximately 6 years. Management of hyperglycemia has become increasingly complex: it involves now at least 12 different classes of glucose-lowering agents in the U.S., and is increasingly costly, resulting in over $\$ 18$ billion in annual expenditures [8].

\section{$H b A l c$}

Different diabetes management algorithms have been proposed [9-11], which have similarities and differences: however, most agree with a HbA1c target of $<7.0 \%$ for the majority of people with diabetes, with the exception of the American Association of Clinical Endocrinologists (AACE) [9] which claims for a lower target (HbA1c $<6.5 \%)$, if safely achievable. More or less stringent goals are suggested for selected individual patients, on the basis of the safe achievement of the target (HbA1c $\leq 6.5 \%)$ or for patients with concurrent illness and at risk for hypoglycemia (HbAlc between $>6.5$ and $<8 \%$ ). Once again, clinical judgment remains paramount in decision. Although not strictly linked to metabolic targets, some inconsistency is present in diagnostic recommendations: for the American Diabetes Association [11], for example, people with $\mathrm{HbA1c}$ value between 5.7 and $6.4 \%$ constitute a category at increased risk of diabetes (prediabetes), while for the World Health Organization [12] there is currently insufficient evidence to make any formal recommendation on the interpretation of $\mathrm{HbA} 1 \mathrm{c}$ levels below $6.5 \%$. Moreover, providing specific targets for diagnosis has limitations which are also acknowledged by ADA: "risk is continuous extending below the lower limit of the range $(5.7 \%)$ and becoming disproportionately greater at the higher end of the range $(6.5 \%)$." Perhaps time has come for clinicians to use multiple sources of information to assess glycemia, including fructosamine and glycated albumin, as performance of combination testing was better than $\mathrm{HbA} 1 \mathrm{c}$ alone for the diagnosis of incident diabetes [13].

\section{LDL-cholesterol}

The recently released 2013 American College of Cardiology/ American Heart Association (ACC/AHA) guideline [14] on the treatment of blood cholesterol to reduce atherosclerotic cardiovascular risk in adults recommends moderate-intensity statin therapy for primary prevention for persons aged 40-75 years with type 1 or 2 diabetes and LDL-cholesterol levels between 70 and $189 \mathrm{mg} / \mathrm{dl}$ (level $A$ ); high-intensity statin therapy may reasonable, unless contraindicated, for those diabetic patients with an estimated 10-year cardiovascular risk $\geq 7.5 \%$ (expert opinion). High-intensity statin therapy lowers LDL-cholesterol level by approximately $\geq 50 \%$ on average and can be obtained with atorvastatin (40-80 mg daily) or rosuvastatin (20-40 mg daily). Moderate-intensity statin therapy lowers LDL-cholesterol level by approximately 30 to $<50 \%$ on average. 
Table 1 Recent recommendations by Scientific Associations for metabolic targets in people with diabetes

\begin{tabular}{|c|c|c|c|}
\hline & $\mathrm{HbA} 1 \mathrm{c}(\%)$ & LDL-cholesterol (mg/dl) & $\begin{array}{l}\text { Blood pressure } \\
(\mathrm{mmHg})\end{array}$ \\
\hline ADA, 2014 & $<7 \%$, for many patients & $<100$, without CVD $<70$, with CVD & $<140 / 90$ \\
\hline (level of evidence) & $\mathrm{B}$ & $\mathrm{B}$ & $\mathrm{B}$ \\
\hline AACE/ACE, 2013 & $<6.5 \%$, for healthy patients & $<100$, moderate risk $<70$, high-risk & $\sim 130 / 80$ \\
\hline (level of evidence) & Expert opinion & Expert opinion & Expert opinion \\
\hline $\begin{array}{l}\text { JNC8, } 2014 \\
\text { (level of evidence) }\end{array}$ & - & - & $\begin{array}{l}<140 / 90 \\
\mathrm{E}\end{array}$ \\
\hline $\begin{array}{l}\text { ACC/AHA, 2013/2014 } \\
\text { (level of evidence) }\end{array}$ & - & $\begin{array}{l}\text { No target level High statin: estimated } \\
10 \text {-year CVD risk } \geq 7.5 \% \\
\text { E }\end{array}$ & - \\
\hline $\begin{array}{l}\text { ESC/EASD, } 2013 \\
\text { (level of evidence) }\end{array}$ & $\begin{array}{l}<7 \% \\
\mathrm{C}^{\dagger} \\
\text { Prevention of CVD }\end{array}$ & $\begin{array}{l}<100 \text {, high risk }<70, \text { very-high risk } \\
\text { A }\end{array}$ & $\begin{array}{l}<140 / 85 \\
\text { A }\end{array}$ \\
\hline
\end{tabular}

$A D A$ American Diabetes Association, AACE American Association of Clinical Endocrinologists, JNC8 Eight Joint National Committee, ACC American College of Cardiology, AHA American Heart Association, ESC European Society of Cardiology, EASD European Association for the Study of Diabetes, CVD cardiovascular disease, level of evidence B supportive evidence from well-conducted cohort and case-control studies, level of evidence $E$ insufficient evidence or evidence unclear (expert opinion). $C^{\dagger}$ Consensus of opinion of the experts, level of evidence $A$ data derived from multiple randomized clinical trials or meta-analyses, $\sim$ approximately

\section{Blood pressure}

The Eighth Joint National Committee (JNC 8) released the 2014 evidence-based guideline for the management of high-blood pressure in adults [15]. In the population aged 18 years or older with diabetes, pharmacologic treatment should be initiated at systolic pressure (SP) of $140 \mathrm{mmHg}$ or higher, or diastolic pressure (DP) of $90 \mathrm{mmHg}$ or higher, and treat to a goal SP of lower than $140 \mathrm{mmHg}$ and a goal DP lower than $90 \mathrm{mmHg}$ (expert opinion). The panel also recognizes that goals of lower than $130 \mathrm{mmHg}$ for SP and lower than $80 \mathrm{mmHg}$ for DP are commonly recommended for adults with diabetes and hypertension, without sufficient evidence to support these lower goals.

The recent lipid and blood pressure guidelines have generated much debate within the scientific arena, from the peril of global statinization [16], to the need to harmonize the many cardiovascular risk guidelines and recommendations, to the need of randomized clinical trials that looks at the real-world generalizability [17].

\section{Difference and similarities}

There are differences and similarities among these recent guidelines for people with diabetes [9-11, 14, 16]. As indicated in Table 1, the main differences relate to the level of the evidence, which may vary sharply: for blood pressure targets, ESC/EASD guidelines used the highest level (A), while the JNC8 used the lowest level (E). There are recommendations based on expert opinions (insufficient evidence or evidence is unclear or conflicting) in almost all guidelines, including the HbA1c target of $\leq 7.0 \%$ for the prevention of CVD (ESC/EASD), high-intensity statin therapy for people with an estimated 10-year CVD risk $\geq 7.5 \%$ (AHA/ACC), and the blood pressure target $<140$ / $90 \mathrm{mmHg}$ (JNC8). All the recommendations released by ACCE/ACE are based on expert opinion, as "participating clinical experts utilized their judgment and experience" [9].

\section{Conclusions}

Failure to treat to target, or prescribing that is not concordant with guidelines are being referred to as clinical inertia [18]. Medicine is an applied science and, as such, complete certainty in clinical medicine is unattainable. Moreover, the same science can be applied in different ways by different doctors. This may be one reason why the ACC/AHA guidelines no longer emphasize the achievement of LDL-cholesterol target in diabetes: taking a statin may be enough, as this has been shown to reduce cardiovascular outcomes.

Guideline recommendations impact on thousands of general practitioners and specialists, and hence on millions of diabetic patients. Clinicians should have confidence in the recommendations: the fact that recommendations for some metabolic targets in diabetic patients are based on expert opinions is not necessarily a harm, as the skill of the physician cannot be codified into any rigid or mathematical formula. Unfortunately, we do not have studies available for every question we might ask, and some questions cannot be answered. This is acknowledged in guideline 
recommendations that are said to be not a substitute for clinical judgment [16], as the ultimate decision about care of a particular patient must be made by in light of the circumstances presented by that patient: situations might arise in which deviations from these guidelines may be appropriate [14]. At very last, the way to manage unavoidable guideline uncertainty is left to clinicians: clinician's opinion does matter.

Conflict of interest The authors declare no conflict of interest.

\section{References}

1. A. Tversky, D. Kahneman, Judgment under uncertainty: heuristics and biases. Science 185, 1124-1131 (1974)

2. D.L. Sackett, W.M. Rosenberg, The need for evidence-based medicine. J. R. Soc. Med. 88, 620-624 (1995)

3. D. Bailey, E. Zanders, P. Dean, The end of the beginning for genomic medicine. Nat. Biotechnol. 19, 207-209 (2001)

4. J.J. Goldberger, A.E. Buxton, Personalized medicine versus guideline-based medicine. J. Am. Med. Assoc. 309, 2559-2560 (2013)

5. K. Esposito, A. Ceriello, D. Giugliano, Does personalized diabetology overcome clinical uncertainty and therapeutic inertia in type 2 diabetes? Endocrine 44, 343-345 (2013)

6. M.K. Ali, K. McKeever, J.B. Bullard, C.C. Saaddine, G. Cowie, G. Imperatore, E.W. Gregg, Achievement of goals in U.S. diabetes care, 1999-2010. N. Engl. J. Med. 368, 1613-1624 (2013)

7. The AMD Annals 2010 Working Group. Quality indicators in diabetes care in Italy. (http://www.infodiabetes.it/files/ANNALIAMD/2010/Annali\%202010\%20inglese.pdf page 48). Accessed 15 Jan 2014

8. American Diabetes Association, Economic costs of diabetes in the US in 2012. Diabetes Care 36, 1033-1046 (2013)

9. American Association of Clinical Endocrinologists, Comprehensive diabetes management algorithm. Endocr. Pract. 19, 327-336 (2013)
10. L. Rydén, P.J. Grant, S.D. Anker, C. Berne, F. Cosentino, N. Danchin, C. Deaton, J. Escaned, H.-P. Hammes, H. Huikuri, M. Marre, N. Marx, L. Mellbin, J. Ostergren, C. Patrono, P. Seferovic, M. Sousa Uva, M.-R. Taskinen, M. Tendera, J. Tuomilehto, P. Valensi, J.L. Zamorano, ESC Guidelines on diabetes, pre-diabetes, and cardiovascular diseases developed in collaboration with the EASD. Eur. Heart. J 34, 3035-3087 (2013)

11. American Diabetes Association Position Statement, Standards of medical care in diabetes-2014. Diabetes Care 37(Suppl 1), S14S80 (2014)

12. Abbreviated Report of a WHO Consultation. Use of glycated haemoglobin (HbA1c) in the diagnosis of diabetes mellitus. http:// www.who.int/diabetes/publications/report-hba1c_2011.pdf?ua=1. Accessed 13 Feb 2014

13. R.M. Cohen, W.H. Herman. Are glycated serum proteins ready for prime time? Lancet Diabetes Endocrinol (2014). doi:10.1016/ S2213-8587(14)70003-8

14. N.J. Stone, J. Robinson, A.H. Lichtenstein, C.N. Merz, C.B. Blum, R.H. Eckel, A.C. Goldberg, D. Gordon, D. Levy, D.M. Lloyd-Jones, P. McBride, J.S. Schwartz, S.T. Shero, S.C. Jr Smith, K. Watson, P.W. Wilson, ACC/AHA guideline on the treatment of blood cholesterol to reduce atherosclerotic cardiovascular risk in adults. Circulation (2013). doi:10.1161/01.cir. 0000437738.63853.7a

15. P.A. James, S. Oparil, B.L. Carter, W.C. Cushman, C. DennisonHimmelfarb, J. Handler, D.T. Lackland, M.L. Lefevre, T.D. Mackenzie, O. Ogedegbe, S.C. Jr Smith, L.P. Svetkey, S.J. Taler, R.R. Townsend, J.T. Jr. Wright, A.S: Narva, E. Ortiz. 2014 evidence-based guideline for the management of high blood pressure in adults: report from the panel members appointed to the Eighth Joint National Committee (JNC 8). J. Am. Med. Assoc. (2013) doi:10.1001/JAMA.2013.284427

16. J.P. Ioannidis, More than a billion people taking statins? Potential implications of the new cardiovascular guidelines. J. Am. Med. Assoc. (2013). doi:10.1001/jama.2013.284657

17. E.D. Peterson, J.M. Gaziano, P. Greenland, Recommendations for treating hypertension. What are the right goals and purposes? J. Am. Med. Assoc. 311(5), 474-476 (2014)

18. D. Giugliano, K. Esposito, Clinical inertia as a clinical safeguard. J. Am. Med. Assoc. 305, 1591-1592 (2011) 